\title{
Bio-protective potential of lactic acid bacteria: Effect of Lactobacillus sakei and Lactobacillus curvatus on changes of the microbial community in vacuum-packaged chilled beef
}

\author{
Yimin Zhang', Lixian Zhu', Pengcheng Dong ${ }^{1}$, Rongrong Liang ${ }^{1}$, Yanwei Mao', \\ Shubing Qiư ${ }^{2}$, and Xin Luo ${ }^{1,3, *}$
}

\footnotetext{
* Corresponding Author: Xin Luo

Tel: +86-538-8242745, Fax: +86-538-8242745,

E-mail: luoxin@sdau.edu.cn

' Lab of Beef Processing and Quality Control, College of Food Science and Engineering, Shandong Agricultural University, Taian, Shandong 271018, China

${ }^{2}$ The municipal authority affairs administration, Dezhou, Shandong 253076, China

3 Jiangsu Synergetic Innovation Center of Meat

Production and Processing Quality and Safety

Control, Nanjing Jiangsu 210000, China

ORCID

Xin Luo

https://orcid.org/0000-0002-8583-8093
}

Submitted Jul 21, 2017; Revised Sept 4, 2017; Accepted Sept 26, 2017
Objective: This study was to determine the bacterial diversity and monitor the community dynamic changes during storage of vacuum-packaged sliced raw beef as affected by Lactobacillus sakei and Lactobacillus curvatus.

Methods: L. sakei and L. curvatus were separately incubated in vacuumed-packaged raw beef as bio-protective cultures to inhibit the naturally contaminating microbial load. Dynamic changes of the microbial diversity of inoculated or non-inoculated (control) samples were monitored at $4^{\circ} \mathrm{C}$ for 0 to 38 days, using polymerase chain reaction-denaturing gradient gel electrophoresis (PCR-DGGE).

Results: The DGGE profiles of DNA directly extracted from non-inoculated control samples highlighted the order of appearance of spoilage bacteria during storage, showing that Enterbacteriaceae and Pseudomonas fragi emerged early, then Brochothrix thermosphacta shared the dominant position, and finally, Pseudomonas putida showed up became predominant. Compared with control, the inoculation of either L. sakei or L. curvatus significantly lowered the complexity of microbial diversity and inhibited the growth of spoilage bacteria $(\mathrm{p}<0.05)$. Interestingly, we also found that the dominant position of L. curvatus was replaced by indigenous L. sakei after $13 \mathrm{~d}$ for L. curvatus-inoculated samples. Plate counts on selective agars further showed that inoculation with $L$. sakei or L. curvatus obviously reduced the viable counts of Enterbacteraceae, Pseudomonas spp. and B. thermosphacta during later storage ( $\mathrm{p}<$ 0.05), with $L$. sakei exerting greater inhibitory effect. Inoculation with both bio-protective cultures also significantly decreased the total volatile basic nitrogen values of stored samples $(\mathrm{p}<0.05)$.

Conclusion: Taken together, the results proved the benefits of inoculation with lactic acid bacteria especially L. sakei as a potential way to inhibit growth of spoilage-related bacteria and improve the shelf life of vacuum-packaged raw beef.

Keywords: Vacuum-packaged Beef; Lactic Acid Bacteria; Bio-protective; Microbial Diversity; Polymerase Chain Reaction-Denaturing Gradient Gel Electrophoresis (PCR-DGGE)

\section{INTRODUCTION}

Freshness, nutritional value, minimal processing, and low or no chemical additives prompts growing consumer interest towards chilled meat. However, such chilled product is also highly favorable for the growth of microorganisms, due to its high water content and abundant nutrients [1]. In addition to traditional processes like salting and curing, mild preservative methods have been applied in chilled or fresh meat, including high hydrostatic pressure, pulsed electric field, irradiation, ozone, packaging and application of probiotics or targeted metabolites [2-4]. Addition of probiotics is termed as bio-control or bio-preservation [5], 
using a natural microflora to increase safety and to extend shelf life of food products without altering the sensory attributes [6]. Lactic acid bacteria (LAB) as a bio-protective culture has been generally regarded as safe [7] and described as 'food grade' organisms by Bredholt et al [8]. LAB are naturally present in meat or meat products and act as powerful competitors to contaminating pathogenic or spoilage bacteria by producing a wide range of antimicrobial metabolites such as organic acids, bacteriocins and other metabolites [5,9-13].

Previous studies have demonstrated that several LAB strains including Lactobacillus sakei (L. sakei), Lactobacillus plantarum, Lactobacillus animalis, and Lactobacillus curvatus ( $L$. curvatus) have been successfully applied as effective bio-preservation agents in meat and meat products [11,12,14-17]. The inhibitory activity of the bio-protective cultures was evaluated by the reduced number of inoculated pathogenic bacteria or spoilage-related organisms in food $[13,15,16,18,19]$. However, little information is available regarding the impact of such bioprotective cultures on the dynamic changes of the naturally contaminating bacteria in vacuum-packaged raw beef during chilled storage. It is essential to understand the overview of bacterial changes in the microbial community during beef storage, to determine whether bio-cultures exert inhibitory activity at particular stages of storage, and to confirm how much suppression would be produced by the bio-cultures towards the main spoilage flora. Also, in spite of a large literature on the subject, there are few studies focusing on the comparable antibacterial properties of different LAB strains on raw beef, which is very important to select the most suitable strains for a specific food. Thus, the aim of this study was to determine the bacterial diversity and monitor the community dynamic changes during storage of vacuum-packaged sliced raw beef as affected by $L$. sakei or L. curvatus, using the polymerase chain reaction-denaturing gradient gel electrophoresis technique (PCR-DGGE), and to make a comparison between the two strains to select a better bio-culture for raw beef. Moreover, the dominant bacteria at each storage time will be determined by conventional plate count methods, compared to analysis of the main bands on DGGE profiles, to verify the consistency of culture-dependent and independent methods. Also the $\mathrm{pH}$ value, color and total volatile basic nitrogen (TVBN) was measured to examine beef quality and stability upon addition of bio-preservatives.

\section{MATERIALS AND METHODS}

\section{Preparation of the bio-protective culture solutions and samples}

Bio-protective culture solutions: The protective cultures used were commercial cultures Bactoferm B-2 (L. sakei) and SafePro B-LC-48 (L. curvatus) supplied by Chr. Hansen (Copenhagen, Denmark). Each culture was reconstituted according to the manufacturer's instructions. The final culture solution was set to deliver a concentration around $7.5 \log _{10} \mathrm{CFU} / \mathrm{g}$ for the dipped beef samples.

Sample procedures: The beef cattle slaughter procedure was performed according to the guidelines of the Animal Ethics Committee in Shandong Agricultural University as approved by the State Scientific and Technological Commission in November 1988 (China). Twelve conventionally segmented longissimus lumborum (LL, 12th rib to the last lumbar vertebrae, $24 \mathrm{~h}$ postmortem, $\mathrm{pH}_{24 \mathrm{~h}} 5.4$ to 5.7) from six carcasses were selected from a cattle slaughter plant based in Shandong province, China. Muscles from the same animal were pairvacuum packed, placed in a foam box and transported to the laboratory within $2 \mathrm{~h}$. Every treatment was repeated three times on separate days; thus two carcasses were used for one trial.

Tendons were removed aseptically, and the LL was cut perpendicularly to the muscle fibers into $25 \mathrm{~cm}^{2}$ steak samples approximately $2 \mathrm{~cm}$ thick. Fifty-four slices in total were collected from both sides of the LL from one carcass. Those slices were randomly assigned to dip into the $L$. sakei solutions for $30 \mathrm{~s}$ as Ls samples and another 18 slices into L. curvatus solutions as Lc samples, and then both treated samples were drained aseptically for $1 \mathrm{~min}$. The 18 cuts left without treatment were regarded as control samples. All the slices were separately vacuum packed. The vacuum bags were composed of polyamide/ polyethylene film with oxygen permeability $<15 \mathrm{~cm}^{3} / \mathrm{m}^{2} / 24 \mathrm{~h}$ at $25^{\circ} \mathrm{C}, 1 \mathrm{~atm}$, and thickness of $80 \mu \mathrm{m}$. All the samples were collected immediately after inoculation (day 0 ) and at 7, 13, 21, 28,38 days storage at $4^{\circ} \mathrm{C}$. Three packages of Ls, Lc, or control cuts were used for the following analyses at each time interval.

\section{Polymerase chain reaction-denaturing gradient gel electrophoresis procedures}

DNA extraction: Total bacterial DNA was directly extracted from duplicate Ls, Lc, or control samples at each designated time. Twenty-five grams of each sample from 3 cuts was placed into the blender bags (BagFilter 400, Interscience, Mourjou, France) and $225 \mathrm{~mL}$ of sterile $0.85 \%$ peptone saline solution was added. Samples were processed for $60 \mathrm{~s}$ with a blender (BagMixer Interscience, France). Ten milliliters of each sample were centrifuged for $2 \mathrm{~min}$ at $12,000 \times \mathrm{g}$ (5415D, Eppendorf, Germany), and the pellet was collected for the bacterial DNA extraction. The GenElute Kit (Bacterial Genomic DNA Kit, Sigma, St. Louis, MO, USA) was used to make the extraction, according to the manufacturer's protocol, and the DNA solution identification was estimated by agarose gel ( $1 \%$, containing Goldview I) electrophoresis.

Polymerase chain reaction reaction: Nested PCR and touchdown PCR reactions were followed as described by Rochelle [20], Li et al [21], and Hu et al [22] with a small modification. Briefly, the primer pairs were $8 f$ (5'-GGA GAG TTT GAT 
CA/CT GGC T-3') and 798r (5'-CCA GGG TAT CTA ATC CTG TT-3'), which yielded approximately 800 bp 16SrDNA fragments. Amplification reactions were carried out in a 50 $\mu \mathrm{L}$ reaction volume containing Premix Taq $(2 \times) 25 \mu \mathrm{L}$; each primer $2 \mu \mathrm{L}(0.4 \mu \mathrm{M})$, DNA template $(2 \mu \mathrm{L})$, and $\mathrm{ddH}_{2} \mathrm{O}(19$ $\mu \mathrm{L})$. The second round of PCR was carried out using primers gc338f and 518r, which yielded about 230 bp fragments, spanning the $\mathrm{V} 3$ region of the $16 \mathrm{SrDNA}$, as previously described $[7,22]$. The reaction volume was the $50 \mu \mathrm{L}$ system, in which the elements contained were the same as mentioned above. To evaluate the specificity of the amplification, the touchdown PCR program was also employed as described in the previous study [22]. The presence of PCR products was tested by $1.0 \%$ agarose gel electrophoresis.

Denaturing gradient gel electrophoresis analysis: PCR products were analyzed by DGGE using a Bio-Rad D-code apparatus. Samples were applied to $8 \%$ (wt/vol) polyacrylamide gels in $0.5 \times$ Tris base-acetic acid buffer. Parallel electrophoresis experiments were performed at $60^{\circ} \mathrm{C}$ by using gels containing a $30 \%$ to $60 \%$ urea-formamide denaturing gradient $(100 \%$ corresponded to $7 \mathrm{M}$ urea and $40 \%$ (wt/vol) formamide). The gels ran for $16 \mathrm{~h}$ at $75 \mathrm{~V}$, then were stained with ethidium bromide for $5 \mathrm{~min}$, rinsed for $15 \mathrm{~min}$ in distilled water, observed and photographed by the Bio-Rad Gel Doc system (BioRad, Milano, Italy).

Sequencing of DGGE bands: The procedure was performed according to Hu et al [22] except for the following modification. The volume of the eluted sterile water for the DNA from each band was $30 \mu \mathrm{L}$, and consequently, $3 \mu \mathrm{L}$ of the eluted DNA from each DGGE band was re-amplified. Final samples were sent to Sangon Biotech Company (Shanghai, China) for sequencing. GenBank DNA data base was used for the identification of those sequences [23]. Sequences with more than $96 \%$ identity were considered to represent the same genus (speculative species).

\section{Microbiological analysis}

At designated time intervals, duplicate $25 \mathrm{~g}$ meat samples from Ls, Lc, or control cuts were separately placed in blender bags (BagFilter 400, Interscience, France) and $225 \mathrm{~mL}$ of sterile peptone saline solution $(\mathrm{NaCl} 0.85 \%$; peptone $0.1 \%)$ was added. Samples were processed for $60 \mathrm{~s}$ with a blender (BagMixer Interscience, France) and serial diluted 10-fold to the desired dilution. Proper volume of each sample from the desired dilutions was spread on the following culture plates in replication. Plate Count Agar (PCA agar, LuQiao Company, Beijing, China) for total viable counts (TVC) was incubated at $37^{\circ} \mathrm{C}$ for $48 \mathrm{~h}$; Man-Rogosa-Sharpe agar (MRS agar, LuQiao Company, Beijing, China) for $\mathrm{LAB}$ was incubated at $37^{\circ} \mathrm{C}$ for $48 \mathrm{~h}$; violet red bile glucose agar (LuQiao Company, China) for Enterobacteriaceae in overlaid pour plates was incubated at $37^{\circ} \mathrm{C}$ for 48 h. Streptomycin thallous acetate actidione agar (Oxoid, UK) was used for Brochothrix thermosphacta (B. thermosphacta) incubated at $25^{\circ} \mathrm{C}$ for $48 \mathrm{~h}$. Pseudomonas spp. were enumerated on Pseudomonas agar base (Haibo, Qingdao, China) supplemented with cetrimide-fucidin-cephaloridine selective supplement (Haibo Company, China) incubated at $25^{\circ} \mathrm{C}$ for $48 \mathrm{~h}$.

\section{Beef quality measurements}

$p H$ : The $\mathrm{pH}$ value of duplicate samples were determined at 0 , $7,13,21,28$, and 38 days using a portable $\mathrm{pH}$ meter (SenvenGo, Mettlertoledo, Im Langacher Greifensee, Switzerland) which was calibrated in buffers with $\mathrm{pH} 4.00$ and 7.00. The probe was inserted directly into the meat samples. Each sample was measured three times, responding to 3 cuts, and the results were the average of the sample.

Color: At each time interval, duplicate samples were exposed to the air at room temperature for $30 \mathrm{~min}$ before color measurement to allow meat pigment oxygenation. An X-Rite SP62 portable sphere spectrophotometer $(8 \mathrm{~mm}$ diameter aperture, illuminant $\mathrm{A}, 10^{\circ}$ observer; X-Rite Incorporated, Grand Rapids, MI, USA) was used to measure the Commission Internationale de l'Eclairage $L^{*}$ and $a^{*}$ color space of meat samples. At least 6 points were measured on each sample. The results were recorded as the mean of these measurements.

Total volatile basic nitrogen: To measure the TVBN, duplicate $10 \mathrm{~g}$ raw beef portions from Ls, Lc, or control samples were minced, mixed well and placed in conical flasks. Then, $100 \mathrm{~mL}$ of water was added, and the suspension was occasionally agitated until they were filtered after $30 \mathrm{~min}$ of immersion. The filtrates were refrigerated until further use. The TVBN content was measured by semi-micro diffusion method [24,25].

\section{Statistical analysis}

The effects of $L$. sakei and L. curvatus on the microbial load (TVC, total LAB, Enterbacteraceae, Pseudomonas pp. and B. thermosphacta) and beef quality during extended storage were evaluated using the analysis of variance using IBM SSPS Statistic (19.0.0). All the data were represented as mean \pm standard deviation. Duncan's multiple comparisons with $\mathrm{p}$ value threshold of $<0.05$ were used to identify significant differences between microbial counts or means of quality parameters between Ls, Lc, and control treatments at the same storage time, or among different storage times exposed to the same treatment. The fingerprints of the DGGE profile were analyzed using the Quantity one ID analysis software version 4.5 (BioRad, Hercules, CA, USA).

\section{RESULTS AND DISCUSSION}

\section{Denaturing gradient gel electrophoresis profiles}

Dynamic changes of the microbial community profiles during 38 days storage were obtained from the raw beef inoculated 
with L. sakei or L. curvatus (as Ls samples and Lc samples, respectively) and beef samples without any treatment (as control) by using the nested PCR-DGGE (Figure 1). No significant differences were detected in the DGGE profiles in triplicate runs of the same samples. High bacterial diversity and dynamic changes were observed during the 38 days storage. More than 20 different bands were found, of which 16 bands were identified by $16 \mathrm{~S} \mathrm{rDNA}$ sequencing. The GenBank accession numbers for the nucleotide sequences obtained from the DGGE bands are shown in Table 1 . These sequences displayed a greater than 98\% identity with sequences in the GenBank databases except for band 3, which showed $95 \%$ similarity.

Microbial diversity of vacuum-packaged raw beef during the 38 days storage at $4^{\circ} \mathrm{C}$ (control samples): There was a high initial bacterial diversity in the vacuum-packaged raw beef. Seven bands were detected at $0 \mathrm{~d}$ in the control samples, of which band 2 was the most intensive one, suggesting that the corresponding bacteria for this band was the main bacterial contaminant from the slaughter plant, and it was defined as L. sakei according to the sequencing results (Table 1). Bands 1,3 , and 9 in lane $\mathrm{C} 0$ were some uncultured bacteria and un-
Table 1. Microbial genus identification after sequencing of the variable V3 region of the 16S-rDNA genes (230 bp) purified from PCR-DGGE profiles

\begin{tabular}{llcl}
\hline Band No. & Closest relatives & Identity (\%) & Accession No. \\
\hline 1 & Uncultured bacterium & 99 & JF719396.1 \\
2 & Lactobacillus sakei & 100 & AB671579.1 \\
3 & Serratia sp. & 95 & HQ690889.1 \\
4 & Lactobacillus curvatus & 100 & JF756310.1 \\
5 & Enterbacteriaceae bacterium & 99 & JN571324.1 \\
6 & Pseudomonas fragi & 100 & HQ824990.1 \\
7 & Brochothrix thermosphacta & 100 & JF756334.1 \\
8 & Pseudomonas putida & 100 & JF745568.1 \\
9 & Uncultured bacteria & 99 & JN378768.1 \\
10 & Listeria sp. & 100 & JF967622.1 \\
11 & Uncultured Pseudomonas sp. & 99 & FN554308.1 \\
12 & Lactobacillus graminis & 99 & GU470987.1 \\
13 & Leuconostoc mesenteroides & 100 & JF756260.1 \\
14 & Uncultured Lactobacillus & 99 & GU363936.1 \\
15 & Lactobacillus fuchuensis & 100 & JF756333.1 \\
16 & Leuconostoc carnosum & 100 & JF756140.1 \\
\hline PCR-DGGE, polymerase chain reaction-denaturing gradient gel electrophoresis.
\end{tabular}

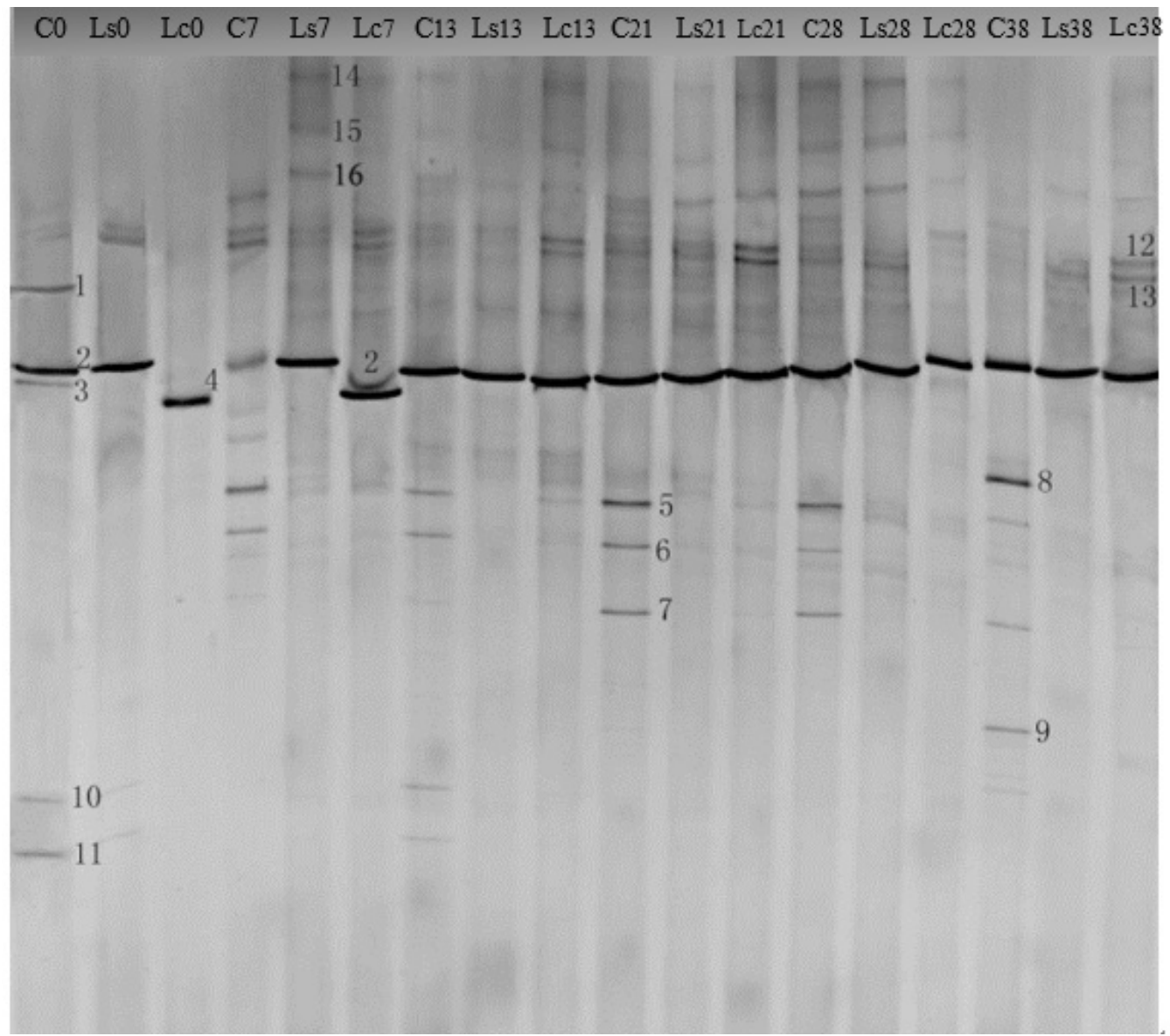

Figure 1. Denaturing gradient gel electrophoresis (DGGE) profile of $16 \mathrm{~S}$ rDNA polymerase chain reaction products recovered from vacuum-packaged raw beef at $4^{\circ} \mathrm{C}$ with or without inoculation of bio-protective cultures for 0 to 38 days. Lanes CO-C38 represent control samples; Lanes LsO- Ls38 represent treatment with protective culture Lactobacillus sakei and Lanes Lc0-Lc38 represent treatment with protective culture Lactobacillus curvatus. Bands indicated by numbers 1-16 were excised, and after reamplification, subjected to sequencing. 
common contaminating bacteria in raw beef, while bands 12 and 13 were very common bacteria found in vacuum-packaged meat, belonging to LAB. Band 10 was identified as Listeria sp., which reflected that the hygiene conditions of the beef processing plant need to improve, as there was a high possibility of the existence of pathogenic bacteria-Listeria monocytogenes in the plant.

The bacterial diversity changed as the storage time extended. L. sakei existed throughout the entire storage period, as well as another two strains of LAB (bands 12 and 13), although only with trace detection. Bands 1 and 3 disappeared on day 7 , while bands 10 and 11 were not detected at later storage intervals, possibly due to the facultative anaerobic environment under vacuum packaging conditions. Bands 5 and 6 emerged in control samples on day 7 (lane C7) and continued to exist until the end. The intensity of bands 7 was very low until day 21 and there was a slight decrease at the final storage period. As shown in Table 1, those bands (5-7) corresponded to Enterbacteriaceae bacterium, Pseudomonas fragi (P. fragi), and B. thermosphacta, respectively. Further, two more bands (8 and 9, lane C38) were discovered at the last sampling day (C38). They were Pseudomonas putida ( $P$. putida) and unknown uncultured bacteria, respectively (Table 1).

Similar to previous observations, this study found that the inherent LAB were not only the main components in the initial composition of contaminating bacteria, but also dominated throughout the entire storage time in the vacuum-packaged meat products [26]. Without regards to LAB, the other main microflora appeared in a relatively regular order during storage. Both Enterbacteriaceae and P. fragi bacteria emerged in the early storage days. $B$. thermosphacta shared the dominant position during the mid-storage times, and at the end, P. putida appeared and became the predominant bacteria. Previous studies found that these bacteria all contributed to beef deterioration. Enterobacteriaceae and B. thermosphacta were the prevailing spoilage organisms in vacuum packaging [1,27] and Pseudomonas spp. were acknowledged as the most dominant genus owing to their capability for glucose and amino acid degradation even in the vacuum-packaged conditions, of which $P$. fragi was the species most frequently isolated from the early stage while $P$. putida showed up in the latter stages of the meat storage $[28,29]$.

Effects of L. sakei and L. curvatus on the microbial community of vacuum-packaged raw beef during 38 days storage at $4^{\circ} \mathrm{C}$ : With the inoculation of L. sakei or L. curvatus, the initial bacterial composition in Ls and Lc samples were dominated by those two bio-protective cultures, respectively (Lanes Ls0 and Lc0). Obviously, Enterbacteriaceae bacterium, P. fragi and $B$. thermosphacta (bands 5, 6, and 7) were completely inhibited during the prolonged storage and P. putida was suppressed until it appeared late in the storage period. Uncultured Lactobacillus, Lactobacillus fuchuensis, and Leuconostoc carnosum corresponded to bands 14,15 , and 16 , respectively, together with Lactobacillus graminis and Leuconostoc mesenteroides (bands 12 and 13), were not significantly influenced by the bio-protective cultures, as those bands were only detected at trace levels in most of the samples across the entire storage period. These results were supported by a number of other studies, of which Katikou et al [6], found two strains of LAB was beneficial in reducing Enterbacteriaceae bacterium and Pseudomonas spp. in vacuum-packaged beef. Castellano et al [15] and Metaxopoulos et al [26] demonstrated that L. curvatus CRL705 and L. curvatus L442 reduced the B. thermosphacta population in meat discs and cured products at chill temperatures, respectively. Some other studies also found LAB could inhibit the growth of spoilage-related bacteria in ground beef, cooked ham or other meat products [16,22], as LAB always serve as powerful competitors to contaminating spoilage bacteria by producing a wide range of antimicrobial metabolites such as organic acids [9].

Additionally, a distinctive result we found was that the dominant position of $L$. curvatus was replaced by indigenous $L$. sakei after 13 days for L. curvatus-inoculated samples (Figure 1). Castellano et al [30] reported that the bio-protective culture L. casei (curvatus) could not completely inhibit the growth of $L$. sakei CRL 1424 when inoculated in the meat slurry at an initial concentration of $3.6 \log \mathrm{CUF} / \mathrm{mL}$. In view of this, in the present study, band 2 shown in Ls samples may be the combination of the inoculated and the indigenous L. sakei strains. We speculated this phenomenon mainly was related to the hydrolysis of arginine. This postulation was also supported by the findings of Chaillou et al [31], who revealed that L. sakei had the ability to degrade the arginine to avoid cell death after glucose depletion, which has an important role for survival of $L$. sakei on meat. However, it should be noted that the inoculated L. sakei and L. curvatus must play a major role in suppressing the spoilage-related bacteria that was observed in this study during the early storage time, as the indigenous L. sakei alone could not inhibit the growth of those bacteria shown in control samples.

\section{Spoilage-related microbial load based on the culture- dependent methods}

As shown in Figure 2, the inoculation of L. sakei and L. curvatus resulted in about $3 \log _{10} \mathrm{CFU} / \mathrm{g}$ higher initial number of TVC than that of control samples $(\mathrm{p}<0.05)$. And the fluctuating values of TVC number were less than 1-unit in both treated samples from the early stages of storage to the end, while the TVC number in control samples increased more than $3 \log _{10}$ $\mathrm{CFU} / \mathrm{g}$ (Figure 2a). The similar growth trends of LAB were found in Figure $2 \mathrm{~b}$. Raw-meat mass and the vacuum-packaging environment provided source and conditions for growth of contaminating LAB, respectively. As shown, those contaminating $\mathrm{LAB}$ adapted well and grew rapidly, then played a role 

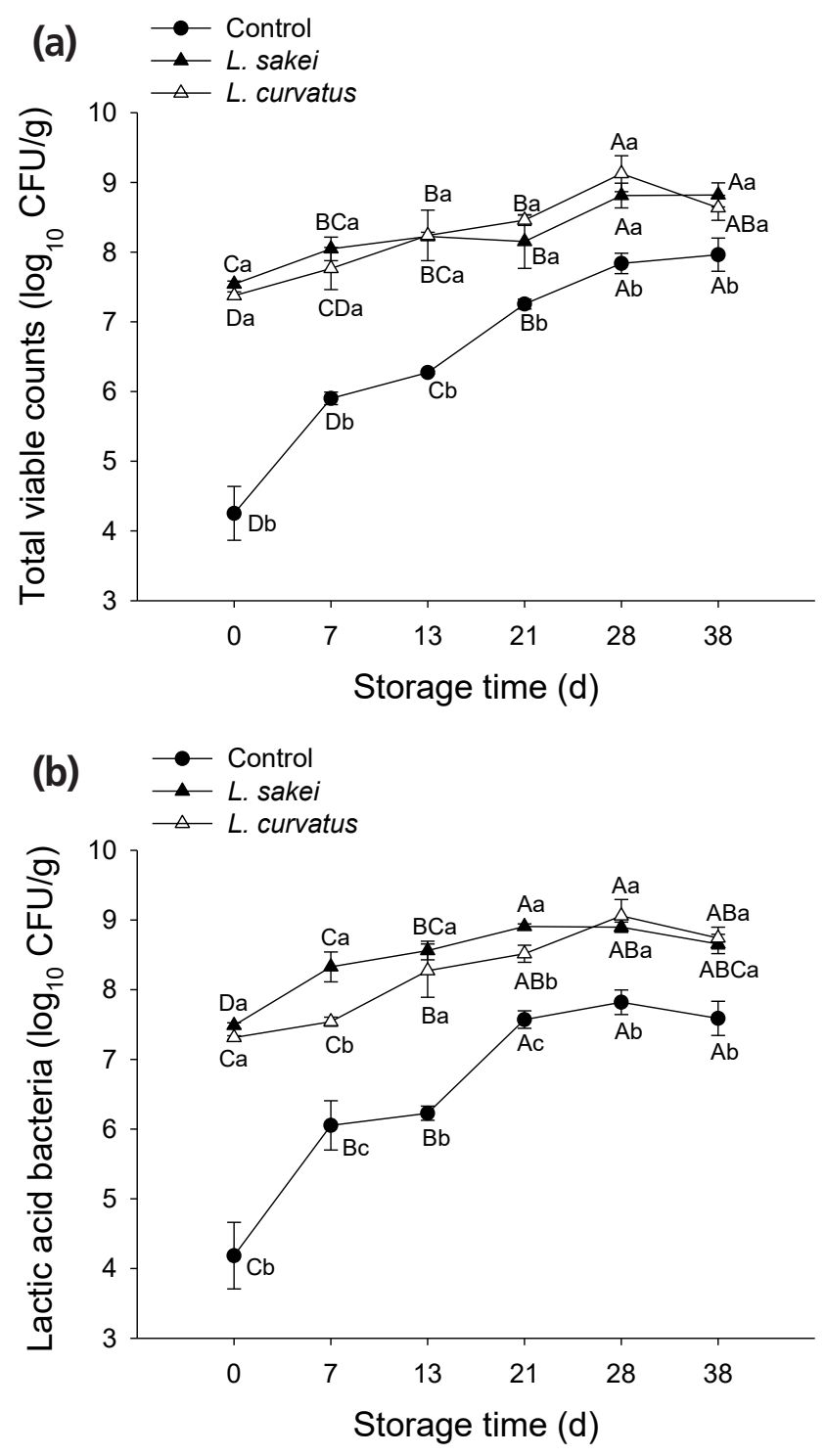

Figure 2. Effect of inoculation with Lactobacillus sakei and Lactobacillus curvatus on total viable counts (TVC) (a) and lactic acid bacteria (LAB) (b) of vacuum-packaged raw beef at $4^{\circ} \mathrm{C}$ for 0 to 38 days. The different uppercase letters (A-D) indicate significant differences between storage times for the same treatment, and the different lowercase letters $(a-c)$ indicate significant differences between treatments at the same time point $(p<0.05)$.

in inhibiting the growth of other bacteria, which was exactly the primary purpose of the vacuum package design for fresh meat. The inoculation of additional LAB in meat products was for the enhancement of those preservative effects. However, most previous studies have paid little attention to this point. As demonstrated above, the DGGE technique application succeeded in distinguishing $L$. sakei and L. curvatus (bands 2 and 4, Figure 1) in the present study, in spite of their close relationship (belonging to the same genus), and resulting in difficulty to separate their effects, especially in meat products [10]. Thus, the plate counts of LAB obtained here included the inoculated and indigenous LAB. Specifically, in Ls samples,
LAB number should be those inoculated L. sakei plus those indigenous $L$. sakei and other LAB in beef samples. Similarly in Lc samples, LAB number should be the inoculated L. curvatus and those indigenous L. sakei as shown in the DGGE profile plus other LAB. These findings provided basic information for the further study about the interactions between inoculated and indigenous LAB cultures, and assist in the selection of better bio-protective cultures for raw meat.

To verify the inhibitory action of $L$. sakei and $L$. curvatus to Enterbacteriaceae Pseudomonas spp. and B. thermosphacta based on the results obtained from DGGE profiles, the culturedependent methods were employed. As shown in Figure 3a$3 c$, the inoculation of bio-protective cultures exhibited a significant inhibitory effect on the growth of those spoilagerelated bacteria. Specifically, both $L$. sakei and $L$. curvatus suppressed the growth of Enterbacteriaceae. Compared with control samples, obvious reduction of the bacterial number was observed at day 13 and day 21 in Ls and Lc samples, respectively. And the reduction was significantly $(\mathrm{p}<0.05)$ greater in Ls samples than that in Lc samples from day 7, indicating that $L$. sakei exerted a stronger inhibitory effect on Enterbacteriaceae than L. curvatus. For Pseudomonas spp. (Figure 3b), there was no significant difference of the growth between treated and control samples at the first 3 weeks storage, while the significant reduction $(\mathrm{p}<0.05)$ of the number in both bioprotected samples was found after 28 days storage, and the reduction was even greater in Ls samples at day 28 . The inhibitory effects of bio-protective cultures on $B$. thermosphacta are shown in Figure $3 c$. No significant $(\mathrm{p}>0.05)$ reduction of this bacterium was found due to the inoculation of $L$. curvatus in raw beef samples during the entire storage period. In contrast, the presence of $L$. sakei inhibited the growth of $B$. thermosphacta to a considerable extent $(\mathrm{p}<0.05)$ throughout the entire storage period. The plate counts results obtained here were consistent with the DGGE results, both showing an effectiveness of the inhibition towards Enterbacteriaceae, Pseudomonas spp. and B. thermosphacta by applying L. sakei and $L$. curvatus in raw beef, which was also in agreement with previous studies mentioned above $[6,15,26]$, mainly due to both strains providing favorable antagonistic activity against those undesired microorganisms [32].

Effect of $L$. sakei and L. curvatus on beef quality traits ( $\mathrm{pH}$, color, and TVBN)

There was no significant difference of the initial $\mathrm{pH}$ values (approximately 5.60) between the control and two treated samples (Table 2). As the storage time extended, the $\mathrm{pH}$ decreased in Ls and Lc samples while no significant changes were observed in control samples. From day 13, the $\mathrm{pH}$ value of the Ls samples decreased to a level lower than Lc and control samples, and the trend continued to day 38 . The Lc samples showed a significantly lower $\mathrm{pH}$ value than that of control 

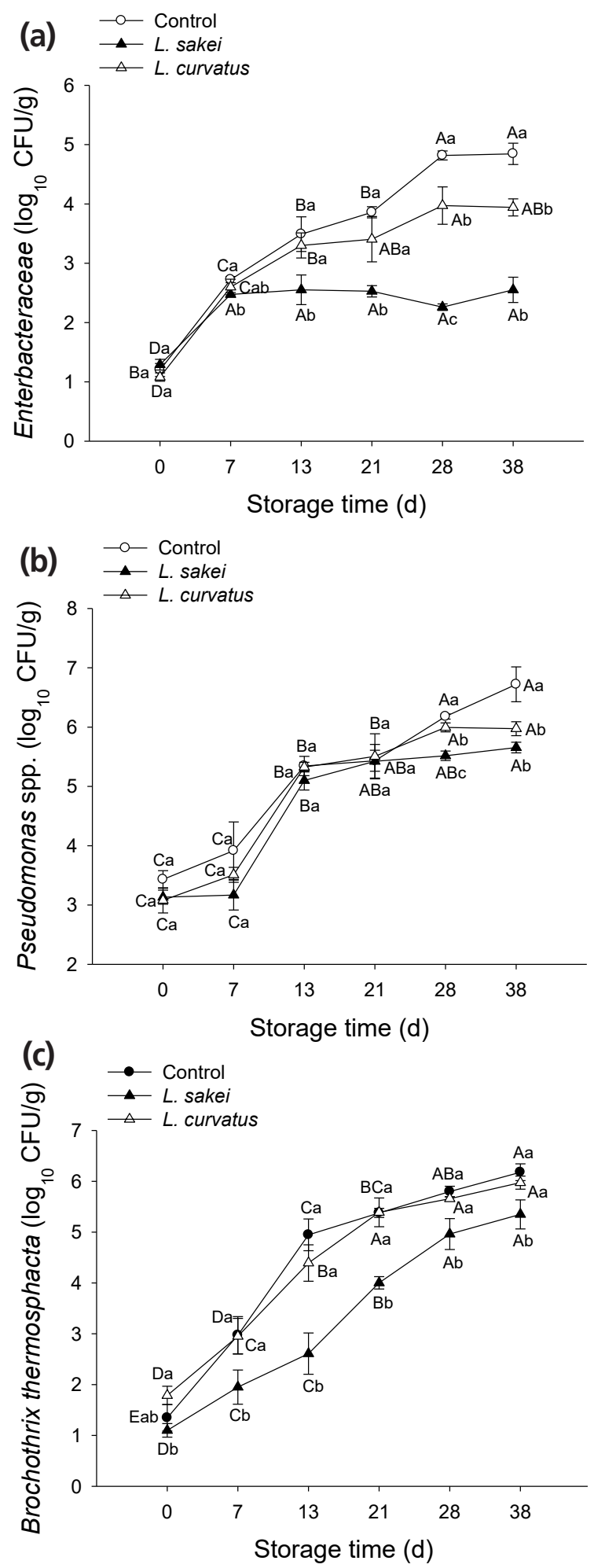

Figure 3. Effect of inoculation with Lactobacillus sakei and Lactobacillus curvatus on growth of Enterbacteraceae (a), Pseudomonas spp. (b), and Brochothrix thermosphacta (c) of vacuum-packaged beef at $4^{\circ} \mathrm{C}$ for 0 to 38 days. The different uppercase letters (A-E) indicate significant differences between storage times for the same treatment, and the different lowercase letters (a-c) indicate significant differences between treatments at the same time point $(p<0.05)$.
Table 2. Effect of Lactobacillus sakei and Lactobacillus curvatus on $\mathrm{pH}$ values of vacuum-packaged raw beef at $4^{\circ} \mathrm{C}$ for 0 to 38 days

\begin{tabular}{lccc}
\hline & Control & Lactobacillus sakei & Lactobacillus curvatus \\
\hline 0 & $5.58 \pm 0.07^{\mathrm{Aa}}$ & $5.55 \pm 0.03^{\mathrm{Aa}}$ & $5.56 \pm 0.05^{\mathrm{Aa}}$ \\
7 & $5.51 \pm 0.04^{\mathrm{Aa}}$ & $5.46 \pm 0.03^{\mathrm{Ab}}$ & $5.50 \pm 0.05^{\mathrm{Aab}}$ \\
13 & $5.53 \pm 0.04^{\mathrm{Aa}}$ & $5.36 \pm 0.02^{\mathrm{Bc}}$ & $5.50 \pm 0.04^{\mathrm{Aab}}$ \\
21 & $5.51 \pm 0.08^{\mathrm{Aa}}$ & $5.32 \pm 0.04^{\mathrm{Bcd}}$ & $5.45 \pm 0.05^{\mathrm{Aabc}}$ \\
28 & $5.50 \pm 0.07^{\mathrm{Aa}}$ & $5.23 \pm 0.09^{\mathrm{Bd}}$ & $5.37 \pm 0.09^{\mathrm{ABb}}$ \\
38 & $5.66 \pm 0.04^{\mathrm{Aa}}$ & $5.27 \pm 0.04^{\mathrm{Ccd}}$ & $5.34 \pm 0.01^{\mathrm{Bb}}$ \\
\hline
\end{tabular}

Values are given as means \pm standard deviation from triplicate determinations.

A.C Means significant differences between storage times for the same treatment $(p<0.05)$.

${ }^{a-d}$ Means significant differences between treatments at the same time point $(p<0.05)$.

samples but still higher than Ls samples only in the last storage day. The final $\mathrm{pH}$ values of samples incubated with $L$. sakei and $L$. curvatus were 5.27 and 5.34, respectively, significantly $(\mathrm{p}<0.05)$ lower than the control sample (5.66). This finding was in agreement with several previous studies, which found that inoculation with LAB had the overall effect of decreasing $\mathrm{pH}$ for meat slurry, beef homogenates and lamb $[11,15,18]$. It is still uncertain, but likely that this small $\mathrm{pH}$ decline contributes to the growth inhibition of other bacteria by LAB.

No significant difference of $L^{*}$ value was observed between treated and control samples immediately after the inoculation (Table 3). But the $L^{*}$ value of Ls and Lc samples became significantly $(\mathrm{p}<0.05)$ higher than that of control samples from day 13 and 28 , respectively. The initial $a^{*}$ value for all treatments was also without any significant difference, and it declined $(p<0.05)$ only at the last storage day in control samples, while both treated samples kept the redness well throughout the storage period (Table 3). The study of Katikou et al [6] also

Table 3. Effect of Lactobacillus sakei and Lactobacillus curvatus on $L^{*}$ value and $a^{*}$ value of vacuum-packaged raw beef at $4^{\circ} \mathrm{C}$ for 0 to 38 days

\begin{tabular}{|c|c|c|c|c|}
\hline Item & & Control & $\begin{array}{c}\text { Lactobacillus } \\
\text { sakei }\end{array}$ & $\begin{array}{c}\text { Lactobacillus } \\
\text { curvatus }\end{array}$ \\
\hline \multirow[t]{6}{*}{$L^{*}$ value } & 0 & $43.7 \pm 0.4^{\mathrm{Aa}}$ & $43.8 \pm 1.1^{\mathrm{Aa}}$ & $44.1 \pm 0.6^{\mathrm{Aa}}$ \\
\hline & 7 & $44.0 \pm 1.3^{\mathrm{Aa}}$ & $45.1 \pm 2.3^{\mathrm{Aa}}$ & $44.3 \pm 1.1^{\mathrm{Aa}}$ \\
\hline & 13 & $44.1 \pm 1.3^{\mathrm{Ba}}$ & $46.4 \pm 0.4^{\mathrm{Aa}}$ & $44.9 \pm 0.6^{\mathrm{ABa}}$ \\
\hline & 21 & $43.7 \pm 1.3^{\mathrm{Ba}}$ & $46.8 \pm 1.6^{\mathrm{Aa}}$ & $46.0 \pm 1.5^{\mathrm{ABa}}$ \\
\hline & 28 & $43.1 \pm 1.0^{\mathrm{Ba}}$ & $46.0 \pm 0.9^{A a}$ & $46.5 \pm 0.6^{\mathrm{Aa}}$ \\
\hline & 38 & $43.1 \pm 1.0^{\mathrm{Ba}}$ & $46.2 \pm 0.5^{\mathrm{Aa}}$ & $46.0 \pm 0.9^{\mathrm{Aa}}$ \\
\hline \multirow[t]{6}{*}{$a^{*}$ value } & 0 & $18.1 \pm 0.4^{\mathrm{Aab}}$ & $18.0 \pm 0.5^{\mathrm{Aa}}$ & $17.9 \pm 0.8^{\mathrm{Aa}}$ \\
\hline & 7 & $20.3 \pm 1.2^{\mathrm{Aa}}$ & $19.2 \pm 0.2^{\mathrm{Aa}}$ & $20.0 \pm 1.2^{\mathrm{Aa}}$ \\
\hline & 13 & $19.2 \pm 1.1^{\text {Aab }}$ & $8.8 \pm 0.3^{\mathrm{Aa}}$ & $18.3 \pm 0.2^{\mathrm{Aa}}$ \\
\hline & 21 & $19.2 \pm 0.7^{\text {Aab }}$ & $18.9 \pm 1.3^{\mathrm{Aa}}$ & $18.7 \pm 0.5^{\mathrm{Aa}}$ \\
\hline & 28 & $18.4 \pm 1.6^{\mathrm{Aab}}$ & $18.1 \pm 1.4^{\mathrm{Aa}}$ & $17.5 \pm 0.8^{\mathrm{Aa}}$ \\
\hline & 38 & $16.7 \pm 1.3^{\mathrm{Ab}}$ & $18.0 \pm 0.3^{\mathrm{Aa}}$ & $19.4 \pm 1.4^{\mathrm{Aa}}$ \\
\hline $\begin{array}{l}\text { Values are } \\
\text { A-B Means } \\
(p<0.05) . \\
\text { a-b Means } s \\
(p<0.05) .\end{array}$ & & erences bety & $\begin{array}{l}\text { tion from triplica } \\
\text { torage times for }\end{array}$ & $\begin{array}{l}\text { determinations. } \\
\text { same treatment } \\
\text { ne time point }\end{array}$ \\
\hline
\end{tabular}


found $\mathrm{LAB}$ treated beef samples were not significantly different with untreated beef, and the $L^{*}$ value showed an increasing trend. Taken together, results indicated that the addition of $L$. sakei and L. curvatus bio-protective cultures on raw beef samples had no negative effect on the beef color, and on the contrary, it seems that $L$. sakei could improve the $L^{*}$ value in the latter stage of storage.

The determination of TVBN or volatile basic nitrogen (VBN) is widely used for evaluating the degree of freshness/ spoilage for raw meat and fish [25,33-36]. With a relatively low initial value $(3.76 \mathrm{mg} / 100 \mathrm{~g})$, TVBN in control samples gradually increased during the first 21 days and increased sharply thereafter (Figure 4). Based on the hygienic standard for fresh/ frozen meat of livestock GB 2707-2016 (China), the beef would be defined as not fresh if the TVBN value was higher than 15 $\mathrm{mg} / 100 \mathrm{~g}$, which is also the maximum acceptable value for consumers [37]. At day 28, the TVBN value in control samples was $15.04 \mathrm{mg} / 100 \mathrm{~g}$, already higher than the acceptable level; and at day 38 , it was $21.54 \mathrm{mg} / 100 \mathrm{~g}$, greatly higher than the benchmark. On the other hand, the TVBN in Ls and Lc samples maintained TVBN values below the acceptable level during the entire storage time. Even at the last storage day ( $38 \mathrm{~d})$, the values were 11.66 and $9.82 \mathrm{mg} / 100 \mathrm{~g}$ for Ls and Lc samples, respectively. This result demonstrated that both $L$. sakei and L. curvatus exerted a protective action for the vacuum-packaged raw beef through reducing the production of TVBN.

While TVBN is a very important meat spoilage indicator, some previous studies evaluated the effectiveness of bio-protective cultures on meat quality as measured by a sensory panel. Similarly with our study, those findings also showed that the inoculation of bio-protective cultures could maintain meat

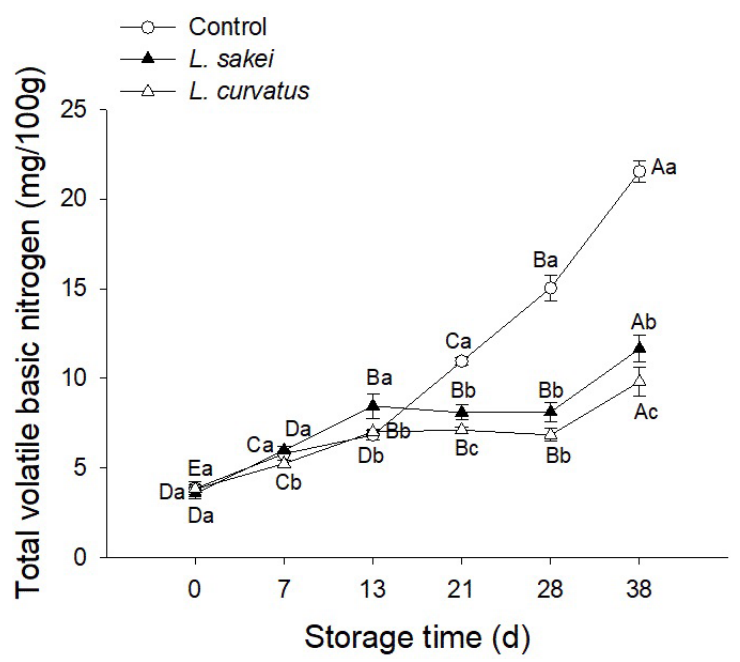

Figure 4. Effect of inoculation with Lactobacillus sakei and Lactobacillus curvatus on total volatile basic nitrogen (TVBN) of vacuum-packaged raw beef at $4^{\circ} \mathrm{C}$ for 0 to 38 days. The different uppercase letters (A-E) indicate significant differences between storage times for the same treatment, and the different lowercase letters $(a-c)$ indicate significant differences between treatments at the same time point $(p<0.05)$. quality and prolong the shelf life, compared to non-inoculated controls [18]. Additionally, those studies found that the application of bio-protective cultures in fresh meat had no negative effects on the sensory attributes $[6,18,38]$.

Overall, no negative beef quality traits were found in the beef samples inoculated with $L$. sakei or L. curvatus. Both cultures improved the lightness at the latter stage of storage and decreased the content of TVBN throughout the entire store period. The $\mathrm{pH}$ value was somewhat lower in L. sakei inoculated beef samples than non-inoculated samples, but this decline was acceptable according to previous research [15].

\section{CONCLUSION}

The bacteriostatic activity of two LAB strains (L. sakei and $L$. curvatus) as bio-protective cultures in vacuumed-packaged raw beef at $4^{\circ} \mathrm{C}$ were evaluated by using both culture-independent and culture-dependent methods. The PCR-DGGE results demonstrated that the inoculation of either L. sakei or L. curvatus significantly lowered the complexity of microbial diversity and slowed down the growth of spoilage bacteria during the whole storage time, which coincided with a marked reduction of the viable counts of Enterbacteraceae, Pseudomonas spp. and $B$. thermosphacta using appropriate selective media. Moreover, inoculation of LAB had some positive improvement on beef quality characteristics, especially for $L$. sakei inoculation treatment. Future efforts should also be oriented towards expanding our knowledge regarding the interaction between inoculated bio-protective cultures and the indigenous $\mathrm{LAB}$ in raw beef.

\section{CONFLICT OF INTEREST}

We certify that there is no conflict of interest with any financial organization regarding the material discussed in the manuscript.

\section{ACKNOWLEDGMENTS}

This work was supported by the National Beef Cattle Industrial Technology System (CARS-37), funds for Shandong province agricultural innovation team (SDAIT-09-09) and funds of Shandong "Double Tops" Program (SYL2017XTTD12).

\section{REFERENCES}

1. Ercolini D, Russo F, Torrieri E, Masi P, Villani F. Changes in the spoilage-related microbiota of beef during refrigerated storage under different packaging conditions. Appl Environ Microbiol 2006;72:4663-71.

2. Behsnilian D, Butz P, Greiner R, Lautenschlaeger R. Processinduced undesirable compounds: Chances of non-thermal 
approaches. Meat Sci 2014;98:392-403.

3. Theron MM, Lues JFR. Organic acids and meat preservation: A review. Food Rev Int 2007;23:141-58.

4. Zhou GH, Xu XL, Liu Y. Preservation technologies for fresh meat - A review. Meat Sci 2010;86:119-28.

5. Lucke FK. Utilization of microbes to process and preserve meat. Meat Sci 2000;56:105-15.

6. Katikou P, Ambrosiadis I, Georgantelis D, Koidis P, Georgakis SA. Effect of Lactobacillus-protective cultures with bacteriocinlike inhibitory substances' producing ability on microbiological, chemical and sensory changes during storage of refrigerated vacuum-packaged sliced beef. Int J Food Microbiol 2005;99: 1303-13.

7. Adams MR, Marteau P. On the safety of lactic-acid bacteria from food. Int J Food Microbiol 1995;27:263-4.

8. Bredholt S, Nesbakken T, Holck A. Protective cultures inhibit growth of Listeria monocytogenes and Escherichia coli $\mathrm{O} 157$ : H7 in cooked, sliced, vacuum- and gas-packaged meat. Int J Food Microbiol 1999;53:43-52.

9. Castellano P, Raya R, Vignolo G. Mode of action of lactocin 705, a two-component bacteriocin from Lactobacillus casei CRL705. Int J Food Microbiol 2003;85:35-43.

10. Champomier-Verges MC, Chaillou S, Cornet M, Zagorec M. Erratum to "Lactobacillus sakei: recent developments and future prospects" [Research in Microbiology 152 (2001) 839]. Res Microbiol 2002;153:115-23.

11. Jones RJ, Wiklund E, Zagorec M, Tagg JR. Evaluation of stored lamb bio-preserved using a three-strain cocktail of Lactobacillus sakei. Meat Sci 2010;86:955-9.

12. Li P, Luo H, Kong B, Liu Q, Chen C. Formation of red myoglobin derivatives and inhibition of spoilage bacteria in raw meat batters by lactic acid bacteria and Staphylococcus xylosus. LWTFood Sci Technol 2016;68:251-7.

13. Todorov SD, Stojanovski S, Iliev I, et al. Technology and safety assessment for lactic acid bacteria isolated from traditional Bulgarian fermented meat product "lukanka". Braz J Microbiol 2017;48:576-86.

14. Castellano P, Aristoy MC, Sentandreu MA, Vignolo G, Toldrá F. Lactobacillus sakei CRL1862 improves safety and protein hydrolysis in meat systems. Appl Environ Microbiol 2012; 113:1407-16.

15. Castellano P, Vignolo G. Inhibition of Listeria innocua and Brochothrix thermosphacta in vacuum-packaged meat by addition of bacteriocinogenic Lactobacillus curvatus CRL705 and its bacteriocins. Lett Appl Microbiol 2006;43:194-9.

16. Chaillou S, Christieans S, Rivollier M, et al. Quantification and efficiency of Lactobacillus sakei strain mixtures used as protective cultures in ground beef. Meat Sci 2014;97:332-8.

17.Tirloni E, Cattaneo P, Ripamonti B, et al. In vitro evaluation of Lactobacillus animalis SB310, Lactobacillus paracasei subsp. paracasei SB137 and their mixtures as potential bioprotective agents for raw meat. Food Control 2014;41:63-8.
18. Castellano P, González C, Carduza F, Vignolo G. Protective action of Lactobacillus curvatus CRL705 on vacuum-packaged raw beef. Effect on sensory and structural characteristics. Meat Sci 2010;85:394-401.

19. Jones RJ, Zagorec M, Brightwell G, Tagg JR. Inhibition by Lactobacillus sakei of other species in the flora of vacuum packaged raw meats during prolonged storage. Food Microbiol 2009;26:876-81.

20. Rochelle PA, Will JAK, Fry JC, et al. Extraction and amplification of $16 \mathrm{~S}$ rRNA genes from deep marine sediments and seawater to assess bacterial community diversity. In: Trevors JT, Elsas JD, editors. Nucleic acids in the environment. Berlin, Germany: Springer-Verlag; 1995. pp. 219-39.

21.Li ZY, He LM, Wu J, Jiang Q. Bacterial community diversity associated with four marine sponges from the South China Sea based on 16S rDNA-DGGE fingerprinting. J Exp Mar Biol Ecol 2006;329:75-85.

22. Hu P, Xu XL, Zhou GH, et al. Study of the Lactobacillus sakei protective effect towards spoilage bacteria in vacuum packed cooked ham analyzed by PCR-DGGE. Meat Sci 2008;80:462-9.

23. Altschul SF, Madden TL, Schaffer AA, et al. Gapped BLAST and PSI-BLAST: a new generation of protein database search programs. Nucleic Acids Res 1997;25:3389-402.

24. Chinese standard GB 5009. 228-2016. Method for analysis of hygienic standard of meat and meat products. Beijing, China: Ministry of Health of the People's Republic of China and Standardization Administration of the People's Republic of China.

25. Huang L, Zhao J, Chen Q, Zhang Y. Nondestructive measurement of total volatile basic nitrogen (TVB-N) in pork meat by integrating near infrared spectroscopy, computer vision and electronic nose techniques. Food Chem 2014;145:228-36.

26. Metaxopoulos J, Mataragas M, Drosinos EH. Microbial interaction in cooked cured meat products under vacuum or modified atmosphere at 4 degrees C. J Appl Microbiol 2002;93: 363-73.

27. Fontana C, Cocconcelli PS, Vignolo G. Direct molecular approach to monitoring bacterial colonization on vacuum-packaged beef. Appl Environ Microbiol 2006;72:5618-22.

28. Molin G, Ternstrom A. Numerical taxonomy of psychrotrophic pseudomonads. J Gen Microbiol 1982;128:1249-64.

29. Sutherland JP, Patterson JT, Murray JG. Changes in the microbiology of vacuum-packaged beef. J Appl Bacteriol 1975;39: 227-37.

30. Castellano PH, Holzapfel WH, Vignolo GM. The control of Listeria innocua and Lactobacillus sakei in broth and meat slurry with the bacteriocinogenic strain Lactobacillus casei CRL705. Food Microbiol 2004;21:291-8.

31. Chaillou S, Champomier-Verges MC, Cornet M, et al. The complete genome sequence of the meat-borne lactic acid bacterium Lactobacillus sakei 23K. Nat Biotechnol 2005;23: 1527-33. 
32. Pothakos V, Devlieghere F, Villani F, Björkroth J, Ercolini D. Lactic acid bacteria and their controversial role in fresh meat spoilage. Meat Sci 2015;109:66-74.

33. Cai J, Chen Q, Wan X, Zhao J. Determination of total volatile basic nitrogen (TVB-N) content and Warner-Bratzler shear force (WBSF) in pork using Fourier transform near infrared (FT-NIR) spectroscopy. Food Chem 2011;126:1354-60.

34. Castro P, Padrón JCP, Cansino MJC, Velázquez ES, Larriva RMD. Total volatile base nitrogen and its use to assess freshness in European sea bass stored in ice. Food Control 2006;17: 245-8.

35.Zhao F, Zhou G, Ye K, et al. Microbial changes in vacuumpacked chilled pork during storage. Meat Sci 2015;100:145-9.
36. Saito K, Ahhmed AM, Kawahara S, et al. Evaluation of the performance of osmotic dehydration sheets on freshness parameters in cold-stored beef biceps femoris muscle. Meat Sci 2009;82:260-5.

37. Chinese standard GB 2707-2016. Standard for fresh (frozen) meat of livestock. Beijing, China: Ministry of Health of the People's Republic of China and Standardization Administration of the People's Republic of China.

38. Babji Y, Murthy TR. Effect of inoculation of mesophilic lactic acid bacteria on microbial and sensory changes of minced goat meat during storage under vacuum and subsequent aerobic storage. Meat Sci 2000;54:197-202. 